\title{
TESTOSTERONE THERAPY COULD BE A POTENTIAL APPROACH FOR TREATMENT OF ELDERLY MALE COVID-19 PATIENTS- A REVIEW
}

\author{
MR Gofur* \\ Department of Veterinary and Animal Sciences, University of Rajshahi, Rajshahi-6205, Bangladesh
}

\begin{abstract}
The emerging SARS-CoV-2 (2019-nCoV) is still following the increasing trend of infection worldwide with an elderly male predominance. Studies reported that majority of male patients with COVID-19 suffer from severe testosterone deficiency and are likely to die from the coronavirus mainly due to a less effective immune response and high level of pro-inflammatory cytokines, a condition called cytokine storm. Testosterone (a steroid having protective anti-inflammatory properties) therapy reduces circulating levels of pro-inflammatory cytokines. Testosterone therapy is effective in the management of elderly Alzheimer's disease where pro-inflammatory cytokines are the potent mediators of inflammatory processes, and aged men having HIV infection. As, currently there is no specific therapeutic drug targeting the SARS-CoV-2, and, considering the present pandemic circumstance, and the immunomodulatory and protective findings of testosterone therapy in previous studies, it can be hypothesized that testosterone therapy could be a potential approach for treatment of elderly male COVID-19 patients.
\end{abstract}

Key words: COVID-19, Cytokine storm, Elderly male, SARS-CoV-2, Testosterone therapy

\section{Introduction}

In the $21^{\text {st }}$ century, the proportion of the elderly population is expected to increase significantly. Given the current SARS-CoV-2 (COVID-19) pandemic, a repeated number of reports consistently stating that elderly patients or patients with comorbidities (e.g., hypertension, diabetes mellitus, chronic obstructive pulmonary disease, cardiovascular disease) mostly associated with advanced age run a greater risk for disease progression and mortality (Zhou et al. 2020, Guo et al. 2020). SARS-CoV-2 infection has also been shown to have a male predominance, like the 2003 SARS-CoV-1 and the 2012 MERS epidemics (Karlberg et al. 2004). Epidemiological data reported male sex among deceased patients as high as $73 \%$ in China (Chen et al. 2020b), 72\% in Pakistan (Global Health 50/50 Report 2020), and 70\% in Italy (Onder et al. 2020), thus highlighting that worldwide case fatality rates were almost three times higher in men than in women, indicating a firm gender inequality in SARS-CoV-2-associated sequelae. It has been suspected that testosterone, the principle male sex hormone, may play a potential role in defining age and sex-related differences in terms of SARS-CoV-2 infection-incidence and clinical outcomes.

*Author for correspondence: royhangm@gmail.com 
Currently, there is no specific therapeutic drug targeting the SARS-CoV-2. It remains a major challenge to decide what potential therapeutic regimens to prevent and treat the severely sick COVID-19 patients. Effective vaccines are essential to combat against the extremely contagious SARS-CoV-2. For this, a lot of research efforts have been invested to develop vaccines around the world. Until we have specific therapeutic drugs or vaccines (effective and variant specific) targeting SARS-CoV-2, strategies including early diagnosis, timely reporting, isolation, and supportive treatments are important line of actions against the pandemic COVID-19. At present, the treatments of COVID-19 patients are mainly repurposing the available therapeutic drugs like antiviral drugs, systemic corticosteroids, and anti-inflammatory drugs, and based on symptomatic conditions. In this context, it is important to consider potential role of testosterone (a steroid having protective anti-inflammatory properties) in developing treatment strategies for COVID-19 patients.

\section{Association between testosterone and COVID-19}

Above 95\% testosterone is produced by the Leydig cells, present in between the seminiferous tubules of testis (Gofur and Ogawa 2019, Gofur et al. 2020), in man. Normal testosterone production in man ranges between 4 and 8mg/d. Generally, a normal circulating testosterone level exerts protective effects on respiratory system as it can improve the forced expiratory volume in one second and forced vital capacity (Mohan et al. 2015). Moreover, testosterone is evident to reduce inflammation through down regulating some important pro-inflammatory cytokines, including IL-1 $\beta$, IL-6, and TNF- $\alpha$. Testosterone is a strong regulator of its own production through negative feedback mechanism of the hypothalamic-pituitary-gonadal axis under the influence of luteinizing hormone. However, basal levels of total plasma testosterone are known to have a progressive age-related decrease (hypogonadism) after age 50 (Kim 1999, Kelly and Jones 2013). Low plasma testosterone is also observed in men with comorbidities like obesity, diabetes and obstructive sleep apnea (Bhasin et al. 2018), and such comorbidities are highly prevalent in COVID-19 patients, and thus consider as risk factors for COVID-19 (Mehra et al. 2020).

SARS-CoV-2 infects cells after entering through the angiotensin-converting enzyme II receptor (ACE2R) of ACE2 expressing cells (mainly present on alveolar epithelial type II cells, also on heart, kidney, endothelium, gut and testis cells) of the body (Leung et al. 2020) and leads to the downregulation of ACE2 levels. It should be noted that, the ACE2 plays a vital role in lung protection and testicular function. This suggests that SARSCOV2 infection can occur in all cells with ACE2 receptors. The amount of ACE2 mRNA and protein expression within the testes is higher than in many other tissues (Fan et al. 2020). ACE2 expression has been demonstrated in testicular tissue, seminiferous duct tissues, spermatogonia, Leydig cells and Sertoli cells (Shen et al. 2020, Wang and Xu 2020). ACE2 is a constitutive product of adult-type Leydig cells (Douglas et al. 2004). It can therefore be posited that COVID-19 infection will damage testicular structures and affect both in sperm production and androgens, particularly testosterone secretion (Okçelik 2021). A recent study found that testosterone/luteinizing hormone ratios were significantly lower in patients with COVID-19 infection (Ma et al. 2020). The blood testicular barrier is not cannot adequately function to prevent passage through the urogenital system during viraemia (Li et al. 2012). Orchitis may occur due to COVID-19 as some other viral diseases including severe acute respiratory syndrome (SARS) virus have also been shown to cause viral orchitis and cause male infertility (Xu et al. 2006). Moreover, suppression of ACE2 expression by inflammatory cytokines accompanied by the decrease of androgens of the elderly, may 
establish a negative correlation between ACE2 expression and COVID-19 mortality (Chen et al. 2020a). Another testosterone level reducing hit could be the induction of cytokine storm, the most widely accepted main culprit of COVID-19-induced damage (Sun et al. 2020). Indeed, it is reported that cytokine storm may suppress steroidogenesis in the testis by inhibiting defined pathways (Hong et al. 2004, Guzmán et al. 2010). Therefore, it seems that several conditions are combined in elderly male COVID-19 patients that are associated with low testosterone levels (increasing age, comorbidities, cytokine storm etc.) (Fig. 1). Thus, these multiple testosterone-reducing hits eventually lead to severe deficiencies in testosterone levels in elderly male COVID-19 patients preventing them to mount sufficient immune responses to combat the deadly infection. Moreover, studies from Germany (Schroeder et al. 2020) and Italy (Rastrelli et al. 2021) reported that the majority of male patients with COVID-19 suffer from severe testosterone deficiency and are likely to die from the coronavirus. In a laboratory study, removal of gonads from H1N1 influenza A virus infected male mice resulted in higher death rates compared to gonadally intact male mice (Robinson et al. 2011). In H7N9 infected men, low testosterone levels also correlate with high cytokine responses and lethal outcome (Chen et al. 2020c). Expert commentators have however put forward postulate that low level of testosterone predisposes men to a less effective immune response against infectious agents, and male hypogonadism may trigger a detrimental cytokine dysfunction that might be responsible for adverse clinical outcomes in COVID-19. Therefore, controlling the depletion of this important hormone might be a good option to the COVID-19, especially in males with older age and having a confirmed low blood testosterone level.

\section{The potential roles of exogenous testosterone}

\section{Testosterone as anti-cytokine therapy}

Pro-inflammatory cytokines have a central role in the progression of COVID-19. Moreover, the association between an increase of pro-inflammatory state and decline in testosterone is observed in elderly men (Maggio et al. 2005). Reduction of cytokine activity and/or their receptors (anti-cytokine therapy), can be useful for treatment. In this context testosterone may downregulate inflammation. Several studies showed that testosterone therapy reduce the circulating levels of pro-inflammatory markers (i.e., via inhibition of the NF-kB pro-inflammatory pathway etc.) in patients with testosterone deficiency (hypogonadism) (Fig. 1) (Traish et al. 2018, Mohamad et al. 2019). Like this, testosterone therapy was also effective in the management of elderly named Alzheimer's disease where pro-inflammatory cytokines are the potent mediators of inflammatory processes (Ozen et al. 2007). Moreover, treatment of aged male mice with testosterone improved survival (reduced both mortality and clinical severity) following the 2009 H1N1 influenza A virus infection (Vom Steeg et al. 2016). Immunomodulatory and protective effect of testosterone is evidenced by regulating differentiation of $\mathrm{T}$ lymphocytes. Testosterone replacement effectively inhibits the development of experimental autoimmune orchitis in rats (Fijak et al. 2011). Testosterone therapy is also prescribed to older men living with HIV with testosterone deficiency who are experiencing symptoms of hypogonadism, as men living with HIV who receive testosterone therapy experience faster progression of atherosclerosis, the silent process of damage that precedes a heart attack or other serious cardiovascular event (CORI 2020). Based on the findings of the previous studies, a hypothesis arises that testosterone therapy (as anti-cytokine therapy) may have a role to suppress the progression of COVID-19. 


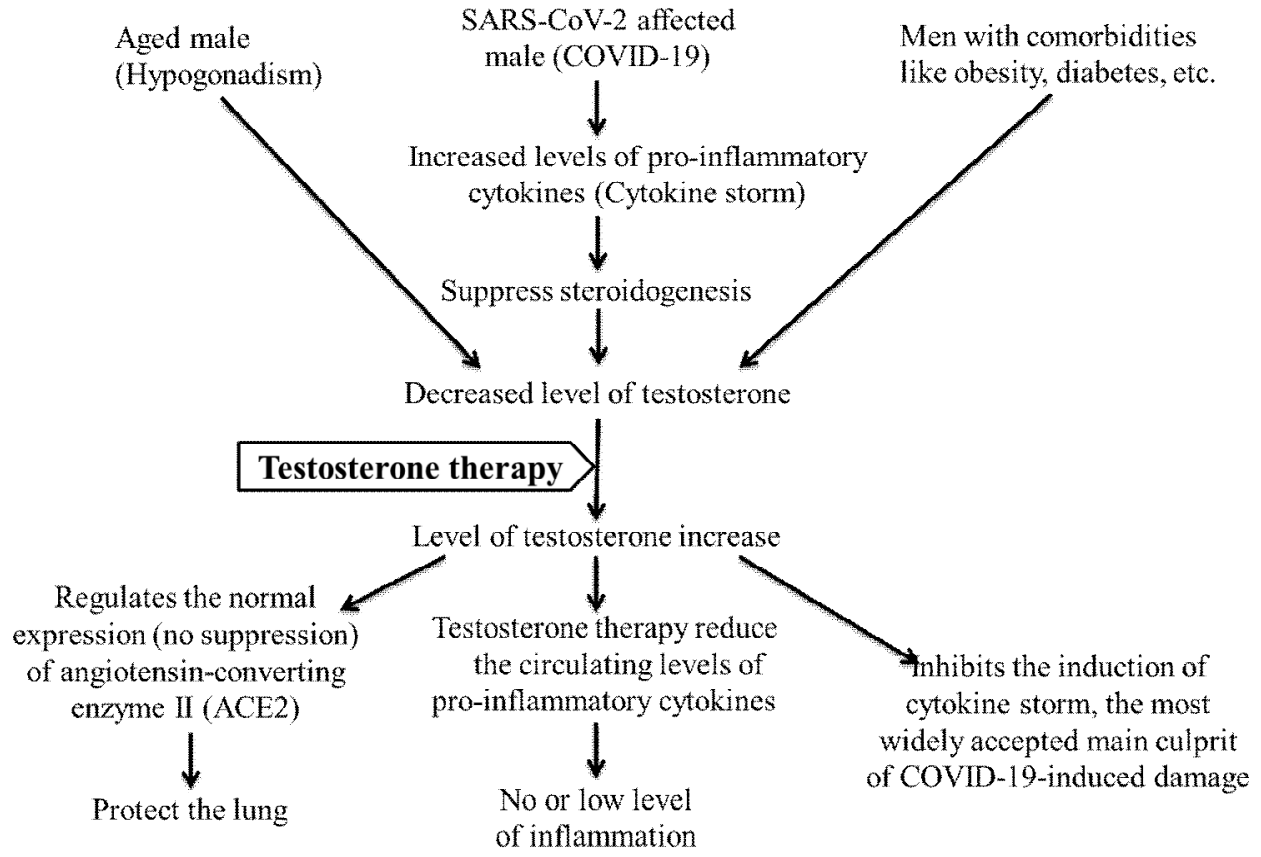

Fig. 1: Possible effects of testosterone therapy.

\section{Anti-inflammatory role of testosterone}

Testosterone can be peripherally converted to estrogen via aromatase enzyme which might add an antiinflammatory impact (Stocco 2012). It is also plausible that testosterone might reduce the need for assisted ventilation through its anti-catabolic role on respiratory muscles (Dillon et al. 2010). A study showed that hypogonadism was common in mechanically-ventilated patients with acute respiratory failure and was strongly associated with longer ICU stays (Almoosa et al. 2014). Several small scale clinical studies indicate that testosterone therapy may improve outcomes in hospitalized chronic obstructive pulmonary disease (COPD) patients (Baillargeon et al. 2019). An improvement in peak oxygen consumption was also observed in men receiving testosterone replacement therapy (Caminiti et al. 2009). Recently, it has been suggested the use of immune modulating drugs or anti-inflammatory drugs to block inflammatory markers to suppress the advancement of COVID-19. Additionally, exogenous testosterone therapy may have therapeutic potential to mitigate the destructive inflammatory response to SARS-CoV-2 without hampering the immune system's response to the virus, as corticosteroids do (Veronese et al. 2020, Wu et al. 2020).

\section{Conclusion and recommendations}

Testosterone therapy has become very popular in recent years. Testosterone therapy is prescribed to elderly men with subnormal level of testosterone to relieve the signs and symptoms of testosterone deficiency. Though there are some controversies on testosterone therapy that testosterone may increase the severity of COVID-19, considering the present pandemic circumstance, and the immunomodulatory and protective findings of testosterone therapy in previous studies, testosterone therapy could be a potential approach for treatment of elderly male COVID-19 patients. Whether testosterone therapy could theoretically be beneficial, clinical trial is needed for therapeutic justification in treating aged men diagnosed with COVID-19. Moreover, 
measuring testosterone levels may be recommended at the time of an identified COVID-19 positive patient as a strategy to identify those at highest risk of severity leading to ICU admission and mortality. The target of testosterone therapy in the elderly male COVID-19 patients is to reach a certain level of plasma testosterone, although the exact level is still under debate. Weksler (Weksler 1995) advocates a serum level of between 240 and $460 \mathrm{ng} / \mathrm{dl}$ as a reasonable target, whereas others (McAlpine and Dobs 1997) recommend a level of 400 and $900 \mathrm{ng} / \mathrm{dl}$ for testosterone therapy in elderly men. However, it should be noted that periodic followup is mandatory during testosterone therapy to detect as early as possible any adverse reactions related to treatment.

\section{References}

Almoosa KF, Gupta A, Pedroza C and Watts NB (2014). Low testosterone levels are requent in patients with acute respiratory failure and are associated with poor outcomes. Endocrine Practice, 20(10): 1057-1063.

Baillargeon J, Urban RJ, Zhang W, Zaiden MF, Javed Z, Sheffield-Moore M, Kuo YF and Sharma G (2019). Testosterone replacement therapy and hospitalization rates in men with COPD. Chronic Respiratory Disease, 16: 1479972318793004.

Bhasin S, Brito JP, Cunningham GR, Hayes FJ, Hodis HN, Matsumoto AM, Snyder J, Swerdloff RS, Wu FC and Yialamas MA (2018). Testosterone therapy in men with hypogonadism: an endocrine society clinical practice guideline. Journal of Clinical Endocrinology and Metabolism, 103(5): 1715-1744.

Caminiti G, Volterrani M, Iellamo F, Marazzi G, Massaro R, Miceli M, Mammi C, Piepoli M, Massimo Fini M and Rosano GMC (2009). Effect of long-acting testosterone treatment on functional exercise capacity, skeletal muscle performance, insulin resistance, and baroreflex sensitivity in elderly patients with chronic heart failure. A doubleblind, placebo-controlled, randomized study. Journal of the American College of Cardiology, 54: 919-927.

Chen J, Jiang Q, Xia X, Liu K, Yu Z, Tao W, Gong W and Han JJ (2020). Individual variation of the SARS-CoV2 receptor ACE2 gene expression and regulation. Aging Cell, 19: e13168. doi: 10.1111/acel.13168.

Chen T, Wu DI, Chen H, Yan W, Yang D, Chen G, Ma K, Xu D, Yu H, Wang H, Wang T, Guo W, Chen J, Ding C, Zhang X, Huang J, Han M, Li S, Luo X, Zhao J and Ning Q (2020). Clinical characteristics of 113 deceased patients with coronavirus disease 2019: retrospective study. British Medical Journal, 368: m1091. https://doi.org/10.1136/bmj.m1295

Chen Y, Bai T, Beck S, Stanelle-Bertram S, Chen T, Dong J, Yang J, Wang L, Wang D, Shu Y and Gabriel G (2020). Low testosterone levels in H7N9 infected men correlate with high cytokine responses and lethal outcome: a retrospective cohort study. MedRxiv, 2020.05.07.20093914; doi: 10.1101/2020.05.07.20093914.

CORI (2020). The Conference on Retroviruses and Opportunistic Infections (CROI) was held from 8 to 11 March 2020. https://www.aidsmap.com/conference/croi-2020.

Dillon EL, Durham WJ, Urban RJ and Sheffield-Moore M (2010). Hormone treatment and muscle anabolism during aging: androgens. Clinical nutrition, 29(6): 697-700.

Douglas GC, O'Bryan MK, Hedger MP, Lee DKL, Yarski MA, Smith AL and Lew RA (2004). The novel AngiotensinConverting Enzyme (ACE) homolog, ACE2, is selectively expressed by adult Leydig cells of the testis. Endocrinology, 145: 4703-11.

Fan C, Li K, Ding Y, Lu W and Wang J (2020). ACE2 expression in kidney and testis may cause kidney and testis damage after 2019-nCoV infection. medRxiv. doi: 10.1101/2020.02.12.20022418.

Fijak M, Schneider E, Klug J, Bhushan S, Hackstein H, Schuler G, Wygrecka M, Gromoll J and Meinhardt A (2011). Testosterone replacement effectively inhibits the development of experimental autoimmune orchitis in rats: evidence for a direct role of testosterone on regulatory T cell expansion. Journal of Immunology, 186: 5162-5172. 
Global Health 50/50 Report (2020). COVID-19 sex-disaggregated data tracker. https://globalhealth5050.org/covid19/

Gofur MR and Ogawa K (2019). Compartments with predominant ephrin-B1 and EphB2/B4 expression are present alternately along the excurrent duct system in the adult mouse testis and epididymis. Andrology, 7(6): 888-901.

Gofur MR, Alam J and Ogawa K (2020). Expression and localisation of ephrin-B1, EphB2, and EphB4 in the mouse testis during postnatal development. Reproductive Biology, 20(3): 321-332.

Guo W, Li M, Dong Y, Zhou H, Zhang Z, Tian C, Qin R, Wang H, Shen Y, Du K, Zhao L, Fan H, Luo S and Hu D (2020). Diabetes is a risk factor for the progression and prognosis of COVID-19. Diabetes Metabolism Research and Reviews, 36: e3319. doi: 10.1002/dmrr.3319.

Guzmán C, Hernández-Bello R and Morales-Montor J (2010). Regulation of steroidogenesis in reproductive, adrenal and neural tissues by cytokines. The Open Neuroendocrinology Journal, 3: 161-9.

Hong CY, Park JH, Ahn RS, Im SY, Choi HS, Soh J, Mellon SH and Lee K (2004). Molecular mechanism of suppression of testicular steroidogenesis by pro-inflammatory cytokine tumor necrosis factor alpha. Molecular and Cellular Biology, 24(7): 2593-604.

Karlberg J, Chong DSY and Lai WYY (2004). Do men have a higher case fatality rate of severe acute respiratory syndrome than women do? American Journal of Epidemiology, 159(3): 229-231.

Kelly DM and Jones TH (2013). Testosterone: a metabolic hormone in health and disease. Journal of Endocrinology, 217(3): 25-45.

Kim YC (1999). Testosterone supplementation in the aging male. International Journal of Impotence Research, 11: 343-352.

Leung JM, Yang CX, Tam A, Shaipanich T, Hackett TL, Singhera GK, Dorscheid DR and Sin DD (2020). ACE-2 expression in the small airway epithelia of smokers and COPD patients: implications for COVID-19. European Respiratory Journal, 55(5): 2000688. doi: 10.1183/13993003.00688-2020.

Li N, Wang T and Han D (2012). Structural, cellular and molecular aspects of immune privilege in the testis. Frontiers in Immunology, 3: 152. doi: 10.3389/fimmu._2012.00152

Ma L, Xie W, Li D , Shi L, Mao Y, Xiong Y, Zhang Y and Zhang M (2020). Effect of SARS-CoV-2 infection upon male gonadal function: A single center-based study. medRxiv 2020.03.21.20037267. doi: 10.1101/2020.03.21.20037267

Maggio M, Basaria S, Ceda GP, Ble A, Ling SM, Bandinelli S, Valenti G and Ferrucci $L$ (2005). The relationship between testosterone and molecular markers of inflammation in older men. Journal of Endocrinological Investigation, 28: 116-119.

McAlpine JN and Dobs AS (1997). Testosterone replacement in the elderly man. In: AUA News January/February 1997.

Mehra MR, Desai SS, Kuy SreyRam, Henry TD and Patel AN (2020). Cardiovascular disease, drug therapy, and mortality in Covid-19. The New England Journal of Medicine, 382: e102.

Mohamad NV, Wong SK, Wan Hasan WN, Jolly JJ, Nur-Farhana MF, Ima-Nirwana S and Chin KY (2019). The relationship between circulating testosterone and inflammatory cytokines in men. Aging Male, 22: 129-40.

Mohan SS, Knuiman MW, Divitini ML, James AL, Musk AW, Handelsman DJ, Beilin J, Hunter M and Yeap BB (2015). Higher serum testosterone and dihydrotestosterone, but not oestradiol, are independently associated with favorable indices of lung function in community-dwelling men. Clinical endocrinology (Oxford), 83: 268-76.

Okçelik S (2021). COVID-19 pneumonia causes lower testosterone levels. Andrologia, 53: e13909. https://doi.org/10.1111/and.13909

Onder G, Rezza G and Brusaferro S (2020). Case-fatality rate and characteristics of patients dying in relation to COVID-19 in Italy. Journal of the American Medical Association, 323(18): 1775-1776. 
Ozen M, Karaahmet F, Tezcan ME, Bulut N and Altundag K (2007). Estrogen or testosterone may be effective agents in the management of both multiple myeloma and Alzheimer's disease. Medical Hypotheses, 1: 231-232.

Rastrelli G, Di Stasi V, Inglese F, Beccaria M, Garuti M, Di Costanzo D, Spreafico F, Greco GF, Cervi G, Pecoriello A, Magini A, Todisco T, Cipriani S, Maseroli E, Corona G, Salonia A, Lenzi A, Maggi M, De Donno G, Vignozzi L (2021). Low testosterone levels predict clinical adverse outcomes in SARS-CoV-2 pneumonia patients. Andrology, 9(1): 88-98.

Robinson DP, Lorenzo ME, Jian W and Klein SL (2011). Elevated 17beta-estradiol protects females from influenza A virus pathogenesis by suppressing inflammatory responses. PLoS Pathogens, 7(7): e1002149.

Schroeder M, Tuku B, Jarczak D, Nierhaus A, Bai T, Jacobsen H, Zickler M, Mueller Z, Stanelle-Bertram S, Meinhardt A, Aberle J, Kluge S and Gabriel G (2020). The majority of male patients with COVID-19 present low testosterone levels on admission to Intensive Care in Hamburg, Germany: a retrospective cohort study. MedRxiv 2020.05.07.20073817; doi:10.1101/2020.05.07.20073817

Shen Q, Xiao X, Aierken A, Yue W, Wu X, Liao M and Hua J (2020). The ACE2 expression in Sertoli cells and germ cells may cause male reproductive disorder after SARS-CoV-2 infection. Journal of Cellular and Molecular Medicine, 24(16): 9472-9477. doi: 10.1111/ jcmm.15541

Stocco C (2012). Tissue physiology and pathology of aromatase. Steroids, 77(1-2): 27-35.

Sun X, Wang T, Cai D, Hu Z, Chen J, Liao H, Zhi L, Wei H, Zhang Z, Qiu Y, Wang J and Wang A (2020). Cytokine storm intervention in the early stages of COVID-19 pneumonia. Cytokine \& Growth Factor Reviews, 53:38-42. doi:10.1016/j.cytogfr.2020.04.002

Traish A, Bolanos J, Nair S, Saad F and Morgentaler A (2018). Do androgens modulate the pathophysiological pathways of inflammation? Appraising the contemporary evidence. Journal of Clinical Medicine, 7(12): 549.

Veronese N, Demurtas J, Yang L, Tonelli R, Barbagallo M, Lopalco P, Lagolio E, Celotto S, Pizzol D, Zou L, Tully MA, llie PC, Trott M, López-Sánchez GF and Smith L (2020). Use of corticosteroids in coronavirus disease 2019 pneumonia: A systematic review of the literature. Frontiers in Medicine (Lausanne), 7: 170. doi: 10.3389/fmed.2020.00170

Vom Steeg LG, Vermillion MS, Hall OJ, Alam O, McFarland R, Chen H, Zirkin B and Klein SL (2016). Age and testosterone mediate influenza pathogenesis in male mice. American Journal of Physiology Lung Cellular and Molecular Physiology, 311(6): L1234-L1244. doi:10.1152/ajplung.00352.2016

Wang Z and Xu X (2020). scRNA-seq profiling of human testes reveals the presence of the ACE2 receptor, a target for SARS-CoV-2 infection in spermatogonia, leydig and sertoli cells. Cells, 9(4): 920. https://doi.org/10.3390/cells9040920

Weksler M (2020). Hormone replacement therapy for men: has the time come? Geriatrics, 50: 52-55.

Wu R, Wang L, Kuo HD, Shannar A, Peter R, Chou PJ, Li S, Hudlikar R, Liu X, Liu Z, Poiani GJ, Amorosa L, Brunetti L and Kong AN (2020). An update on current therapeutic drugs treating COVID-19. Current pharmacology reports, 115. doi: $10.1007 / s 40495-020-00216-7$

Xu J, Qi L, Chi X, Yang J, Wei X, Gong E, Peh S and Gu J (2006). Orchitis: A complication of severe acute respiratory syndrome (SARS). Biology of Reproduction, 74(2): 410-416. https://doi.org/10.1095/biolreprod.105.04477

Zhou F, Yu T, Du R, Fan G, Liu Y, Liu Z, Xiang J, Wang Y, Song B, Gu X, Guan L, Wei Y, Li H, Wu X, Xu J, Tu S, Zhang $Y$, Chen $\mathrm{H}$ and Cao B (2020). Clinical course and risk factors for mortality of adult inpatients with COVID-19 in Wuhan, China: a retrospective cohort study. Lancet, 395(10229): 1054-1062. 